\title{
INCIDÊNCIA - O RETRATO NO TRABALHO ARTÍSTICO E NAS AÇÕES PEDAGÓGICAS
}

\author{
INCIDENCE - THE PORTRAIT IN ARTISTIC WORK AND IN \\ PEDAGOGICAL ACTIONS
}

DOI: http://dx.doi.org/10.5965/1984317813022017220

Maristela Müller - UDESC

\begin{abstract}
RESUMO
No presente relato de experiência pretende-se abordar questões relativas ao retrato enquanto vida e morte, presença e ausência, objeto e gênero artístico, prática artística e prática pedagógica. Não enquanto oposição, mas como contradição, em movimentos conflitantes que, ao mesmo tempo, se complementam em uma relação imbricada do viver. Na parte inicial do texto aborda-se um possível começo do retrato e sua relação com a morte, de acordo com Regis Debray (1994) e Didi-Huberman (1988) que discute os crânios de Jericó adornados, pintados, cuidados e separados dos corpos com base nos estudos de Georges Bataille. Passando pelos retratos funerários de Fayum, para se chegar ao gênero artístico denominado Retrato. A partir dos retratos conhecidos e reconhecidos na história da Arte percebe-se a recorrência de rostos, de alguns traços e características que se assemelham entre as pessoas do passado e do presente. Esta percepção repercute na prática artística e, mais tarde, se converte em prática pedagógica que pode ser lida, vista e refletida a seguir.
\end{abstract}

Palavras-chave: Retrato. História da Arte. Pintura. Trabalho Artístico. Prática Pedagógica.

\begin{abstract}
In this experience report is intended to address issues related to portraiture while life and death, presence and absence, object and artistic gender, artistic practice and pedagogical practice. Not as opposition, but as a contradiction, in conflicting movements that, at the same time, complement each other in a imbricated relationship of living. The initial part of the text presents a possible beginning of the portrait and their relation to death, according to Regis Debray (1994) e Didi-Huberman (1988) which discusses the skulls of Jericho that are adorned, painted, cared and separated of the corpses, based on studies of George Bataille. Passing through the funerary portraits of Fayum, to reach the artistic genre called Portrait. From the portraits known and recognized in the Art History the recurrence of faces is perceived, some traits and characteristics that are similar between people of the past and present. This perception reflects on artistic practice and, later, it becomes a pedagogical practice that can be read, seen and thought out below.
\end{abstract}

Keywords: Portrait. History of Art. Painting. Artistic Work. Pedagogical Practice. 


\section{INTRODUÇÃO}

O presente relato de experiência possui seu repertório embasado em uma prática artística que o antecede. Para alcançar a ação educativa necessita-se apontar para a produção artística e as referências que a embasaram. O relato aborda retratos e a recorrência destes rostos que parecem tão distantes, ao se pensar na história da Arte e, ao mesmo tempo, tão próximos ao se perceber sua reincidência em pessoas do cotidiano.

A série intitulada "Incidência" apresenta um conjunto de trabalhos artísticos que denotam ao encontro e acaso, percebidos pela professora artista, que pode parecer mera coincidência. Encontro de dois rostos que se assemelham em local e tempo diferente no anacronismo dos retratos. Para além da coincidência está a incidência, no sentido de "incidir sobre", que se refere ao ato da artista convidar estas pessoas, cujos rostos se assemelham a um retrato da história da Arte, para participar da ação. O trabalho artístico se resume em aplicar tinta e maquiagem sobre o rosto da pessoa convidada para fotografá-la na mesma posição, de acordo com o retrato ao qual se identificou semelhança, a fim de acentuar a proximidade dos traços.

A prática pedagógica ocorreu posteriormente à prática artística e são próximas. Ao realizar uma sequência de aulas acerca dos diferentes gêneros da pintura (cenas históricas ou mitológicas, retrato, paisagem e natureza-morta) até chegar ao retrato. Foi quando se apresentou uma série de retratos produzidos ao longo da história da Arte, bem como, a prática artística intitulada Incidência. A partir do trabalho artístico os estudantes demonstraram interesse em realizar, na escola, algo que se aproximasse ao que a professora artista havia realizado.

A seguir apresentam-se uma breve reflexão teórica acerca do retrato, seguindo com a prática artística e sua repercussão para se chegar à prática pedagógica realizada com os estudantes. 


\title{
1. A questão do retrato
}

O filósofo francês Georges Didi-Huberman questiona e reflete acerca de um provável começo do retrato. $\mathrm{O}$ que acontece a partir do momento que não se pode mais ver uma pessoa querida? O que acontece quando não se pode mais tocar a pessoa que amamos?

\begin{abstract}
A questão do retrato começa talvez no dia em que, diante de nosso olhar aterrado, um rosto amado, um rosto próximo cai sobre o solo para não se levantar mais. Para finalmente desaparecer na terra e se misturar a ela. A questão do retrato começa talvez no dia em que um rosto começa diante de mim não estar mais aí porque a terra começa a devorá-lo (DIDIHUBERMAN. 1998, p. 62).
\end{abstract}

Para Didi-Huberman, a partir do momento que um rosto querido desfalece, começa a perder sua face, retornar ao pó da terra do qual proveio e por ela ser devorado é que o ser humano sente a necessidade de continuar próximo da pessoa, com seu rosto, seu corpo e sua imagem. Ou seja, é a ausência que gera a necessidade da presença. Quando se perde alguém, junto a esta perda advém o anseio de continuar a ver, tocar e sentir. A perda faz com que se sinta falta daquilo que não está mais presente. Principalmente a partir da morte, da falta e da dor que surge o retrato, como uma maneira de, ainda que ausente, o semblante querido possa se fazer presente.

Georges Didi-Huberman (1988) relaciona o começo do retrato com a morte, da mesma maneira que Regis Debray (1994) compreende o nascimento da imagem e seu envolvimento com a morte. Em oposição a decomposição da morte faz-se a imagem, uma recomposição pela imagem, “(...) uma imagem do inominável, um duplo do morto para mantê-lo vivo" (DEBRAY. 1994, p. 29). Neste sentido "representar é tornar presente o ausente. Portanto, não é somente evocar, mas substituir. Como se a imagem estivesse para preencher uma carência, aliviar um desgosto" (DEBRAY. 1994, p. 38)

Pensar o começo do retrato é diferente de pensar o gênero artístico denominado Retrato, enquanto representação de uma pessoa, como mimese ou cópia, conforme o 
significado da palavra retrato: retrahere, em latim. Didi-Huberman problematiza o retrato em situações que antecede milênios o racionalismo do Renascimento e da criação do gênero artístico. O começo do retrato trata da indagação de um rosto ausente, juntamente com a difícil gestão de sua perda. A dor da perda possui como sintoma a vontade de continuar vendo e estar próximo do ser querido, de manter viva intimamente o imo da pessoa que terra começa a consumir. Assim, para tolerar e gerir a dor surge o retrato, uma presença ausente que alivia, em virtude do anseio de continuar próximo por meio de ser retrato, da sua imagem na substituição ao rosto. Um conforto hodierno que, ao mesmo tempo, alerta a realidade da perda.

\section{Rostos (retratos) de Jericó}

$\mathrm{Na}$ indagação de um rosto ausente junto a difícil gestão de sua perda é possível justificar o começo do retrato, de acordo com Didi-Huberman (1988) que evoca os estudos de Georges Bataille através dos crânios de Jericó, datados entre 8000 e 6000 a.C. Encontrados em sepulturas pré-históricas os crânios foram separados do corpos e preservados. Este ato, não se caracteriza apenas como um sepultamento de crânios ou a separação de relíquias, mas sim de rostos e retratos. Quando encontrados, foi possível apreciar não as aberturas ou buracos vazios das ossadas de cabeças, mas crânios forrados, preenchidos e moldados com argila, com dentes decorados em marfim, pedras e conchas. Ainda, mostravam resquícios de pinturas acastanhadas sobre a cabeça a fim de caracterizar a cor da pele. "Os traços do rosto, o nariz, a boca, as orelhas, as sobrancelhas, foram moldadas com uma delicadeza extraordinária” (DIDI-HUBERMAN. 1998, p. 72). Através da modelagem, do cuidado e dos assessórios agregados aos crânios é sinalizada a problemática do retrato.

Qual pode ser a resposta para que povos pré-históricos realizassem adornos internos e externos em crânios, cuidadosamente preservados e separados de seu corpo. Com relação aos crânios e ao retrato Didi-Huberman menciona que:

Pode bem ser que a questão do retrato dependa, no fim das contas, - ou, antes, no começo - de um ato de ruminação ou de uma pergunta feita ao lugar por aquele que rumina longamente (e visualmente) a morte de seu próximo (DIDI-HUBERMAN. 1998, p. 74). 
$\mathrm{O}$ ato de ruminar significa voltar constantemente à mesma matéria, ou nesse caso, voltar constantemente ao mesmo questionamento sobre o ser e o rosto ausente, a morte, a dor, a perda, a falta, a face sem vida, pálida, descorada, gélida com os olhos cerrados. Voltar constantemente ao retrato, ao rosto, ao cuidado com a face para suportar a perda. Voltar constantemente ao semblante fugidio, que apenas se pode tocar, cuidar, enfeitar, mas que não pode mais nos ver.

Ruminar a morte é um ato questionador e produtor na expectativa de suportar a falta. Por meio dos questionamentos ruminantes acerca da morte é que se pode destacar o começo do retrato, como se, ao modelar, cuidar, refigurar o crânio sem vida fosse possível outra aproximação com aquele ser. No entanto, se é apenas visitado por dentro, onde o rosto perdido se transforma no rosto recordado e cuidado. Com a perda do rosto amado é inventada uma nova face para ser vista: o retrato.

\section{As Tabuinhas de Fayum}

A constatação do começo do retrato ligado à morte é, ao mesmo tempo, espantosa e próxima. Ao sair da pré-história para adentrar na história é possível exemplificar diversas relações entre a morte e o retrato. Pretende-se dar um salto para o Egito, na época da ocupação romana, quando os retratos fúnebres passaram a ser utilizados desde o delta do Nilo até a Núbia. Os retratos de Fayum são retratos realistas realizados sobre pequenas tábuas de madeira que eram colocadas sobre o sarcófago ou caixão e posicionadas no lado de fora, exatamente no lugar onde, por dentro, estava o rosto mumificado.

A madeira utilizada era o carvalho, cedro ou cipreste, sendo que a técnica de pintura também poderia variar entre a encáustica e a têmpera. A encáustica é empregada desde a antiguidade e se caracteriza pelo uso da cera como aglutinante dos pigmentos, deixando a mistura densa e cremosa, tornando a pintura mais resistente às intempéries do tempo. A 
têmpera é uma técnica de pintura na qual os pigmentos ou os corantes também são misturados a um aglutinante, neste caso pode ser uma emulsão de água e gema de ovo, o ovo inteiro, ou somente a clara.

Os retratos de Fayum permitem observar as características de cada pessoa. Se morreu jovem, adulto ou criança, como penteava seu cabelo, como se vestia ou utilizavam joias e adornos. Esta percepção se torna possível em virtude do naturalismo característicos das

pinturas. É este naturalismo que permite identificar os traços das pessoas pintadas há tanto tempo atrás e reencontrar estes traços em outras pessoas na atualidade, seja no formato do rosto, no desenho da sobrancelha, no amendoado dos olhos, no penteado ou no contorno da boca e do nariz, conforme será visto nas Figuras 03, 04 e 05.

\section{O Retrato}

O retrato pictórico é um gênero da pintura que possui como objetivo representar a aparência visual do ser humano, individualmente ou em grupo, embora também possam ser representados animais. Na pintura, o retrato se afirma como gênero artístico autônomo a partir do século XIV, após ter sido utilizado no Egito, no mundo grego e na sociedade romana, com finalidades diversas, seja para comemoração ou por motivo fúnebre. No Renascimento eram representadas as pessoas ricas, os comerciantes, as pessoas da corte e a família ou o próprio artista que produzia seu autorretrato. Com o passar do tempo o retrato difundiu-se entre a classe média por meio de encomendas realizadas. As pinturas de retrato adquirem um lugar de destaque na arte europeia e são produzidas por diferentes escolas e estilos artísticos (Enciclopédia Itaú Cultural, 2017). Atualmente, persiste a pintura de retrato como encomenda de governos, corporações, associações ou indivíduos.

Não se pode deixar de mencionar, rapidamente, a mudança que houve e há nos retratos a partir do advento da fotografia, pois "hoje, tudo existe para terminar numa foto" (SONTAG, 2004, p. 35). O retrato fotográfico difundiu-se com a criação das câmeras portáteis e, atualmente, com as câmeras digitais, desde as profissionais com as lentes removíveis, até as semiprofissionais, os celulares e tablets. Os autorretratos também enchem e impulsionam os ambientes virtuais por meio das self portrait, mais conhecidas como selfs. O trabalho a seguir 
realizado pela professora artista só foi passível de registro por meio da fotografia e do uso de uma câmera portátil digital.

\section{A recorrência dos rostos}

A deflagração da recorrência de alguns rostos pode parecer assombrosa ou engraçada, por isto, com frequência são lançadas reportagens, brincadeiras e matérias sobre pessoas parecidas e que não possuem qualquer parentesco. Com base nesta recorrência de traços que se assemelham entre pessoas que viveram em locais e até em tempos diferentes é que se desenvolve o trabalho artístico intitulado: Incidência.

A série "Incidência" apresenta um conjunto de trabalhos artísticos que denotam ao encontro e acaso, percebidos pela professora artista, que reconhece traços semelhantes entre as pinturas da história da arte e pessoas de seu contexto. Pode parecer mera coincidência, porém o trabalho artístico está para a incidência, no sentido de "incidir sobre". Quando se reconhece a semelhança mencionada, a pessoa é covidada para participar do trabalho e permite que a artista pinte seu rosto e fotografe na mesma posição do(a) retratado(a) na pintura. A prática artística se resume em aplicar tinta e maquiagem sobre o rosto, a fim de acentuar a proximidade dos traços entre um e outro e registrar a ação por meio da fotografia.

A proposta parte da história da Arte, especificamente das pinturas, cujo gênero artístico é denominado Retrato. Pinturas que retratam os rostos, cabeças, com riqueza de detalhes e humanidade. Rostos de pessoas desconhecidas, mas por terem sido representadas de maneira realista, possibilita certa familiaridade a ponto de se tornarem reconhecíveis em outras faces do cotidiano.

A pesquisa parte do pensamento pictórico, mas no trabalho não se trata da pintura de forma tradicional e sim como um desdobramento dela, porque a proposta aparece desprendida da matéria característica, que é tinta sobre tela. Assim, utiliza maquiagens, tinta de rosto, tinta acrílica e lápis aquarelável. Outra diferença encontra-se no suporte, nas pinturas costuma-se utilizar tecido de algodão esticado em bastidor para formar a planaridade da tela e, neste trabalho, utiliza-se o corpo tridimensional, principalmente a cabeça e sua pele onde a 
maquiagem é aplicada para acentuar a semelhança entre os rostos recorrentes do passado e do presente. A partir das memórias da artista é que se identifica a semelhança dos rostos, no anacronismo de retratos, na recorrência dos traços.

Como parte do referencial teórico, além dos autores citados, constam obras e retratos produzidos ao longo da história da Arte. Outra referência são as obras da artista Sindy Shermann, onde ela se coloca no lugar do retratado em uma série de fotografias, conforme pode ser observado no exemplo abaixo (Figura.01), quando Shermann representa a pintura de Caravaggio. As fotografias começaram com mulheres em situações/ cenas clichês e conhecidas advindas de clássicos do cinema, depois com séries publicitárias e pinturas da história de arte. Nelas representou, por exemplo, Marilyn Monroe e Olran, assim como pinturas de Caravaggio e Jean Fouquet.

Outra referência se encontra no cinema onde, constantemente, se (re)constrói personagens, figuras, cenas, e pessoas com base em pinturas, fotografias, desenhos para compor as características dos personagens dos filmes, documentários e biografias. Por exemplo, o filme "Frida" (Figura.02), a partir das fotografias e das pinturas da Frida Kahlo foi possível personificar a atriz Salma Hayek para representar a artista. Outro exemplo é o filme sobre o artista Vermeer intitulado "Moça com brinco de Pérola" que se baseou nas pinturas do artista. Também se pode citar outras produções cinematográficas como: Modigliani, Basquiat, Surviving Picasso, Camille Claudel, Pollock, Moulin Rouge, Klimt, O Sal da Terra, A Pele e A Fotografia Oculta de Vivian Maier. 

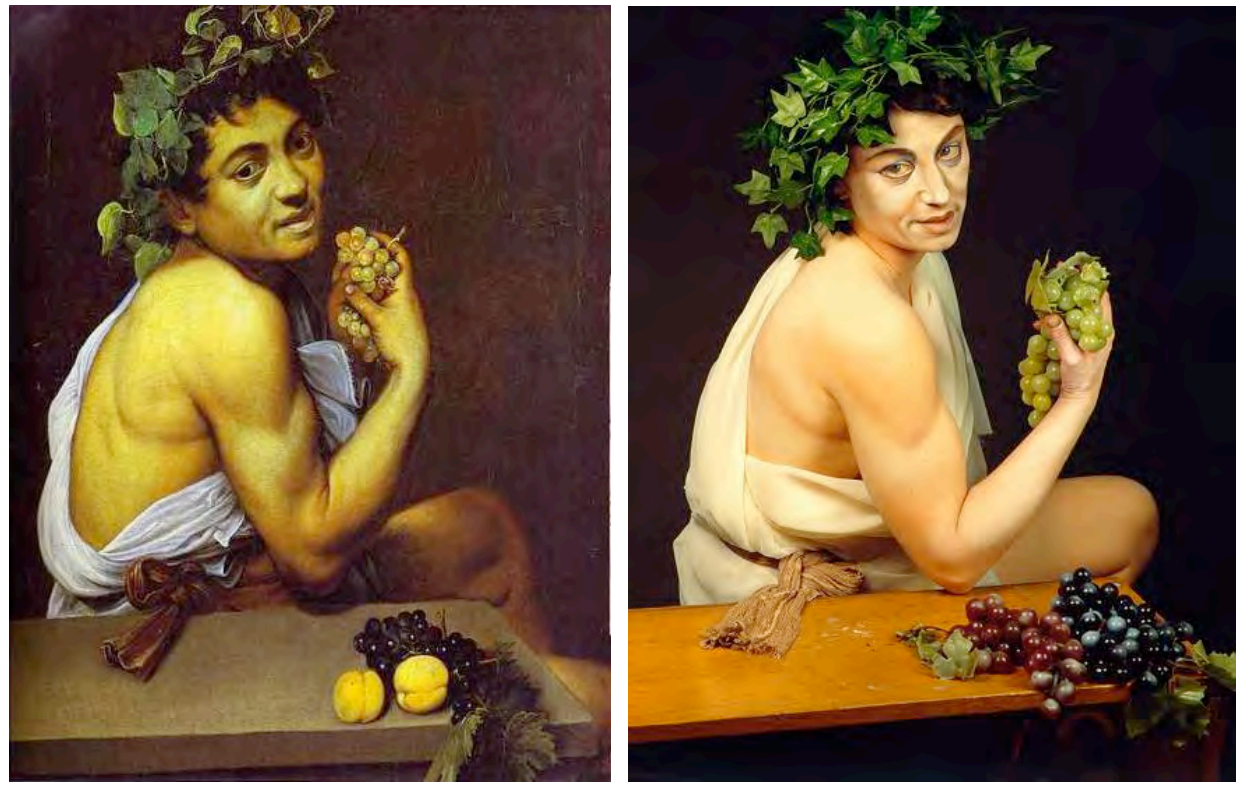

Figura.01 - Lado direito: Pequeno Baco Doente, 1593. Artista: Caravaggio. Técnica: óleo sobre tela. Dimensões: $67 \mathrm{~cm}$ x 53cm. Lado esquerdo: Sem título \#224, 1990. Artista: Sindy Shermann. Técnica: Pintura sobre o corpo e fotografia. Dimensões: $121,9 \mathrm{~cm}$ x $96,5 \mathrm{~cm}$

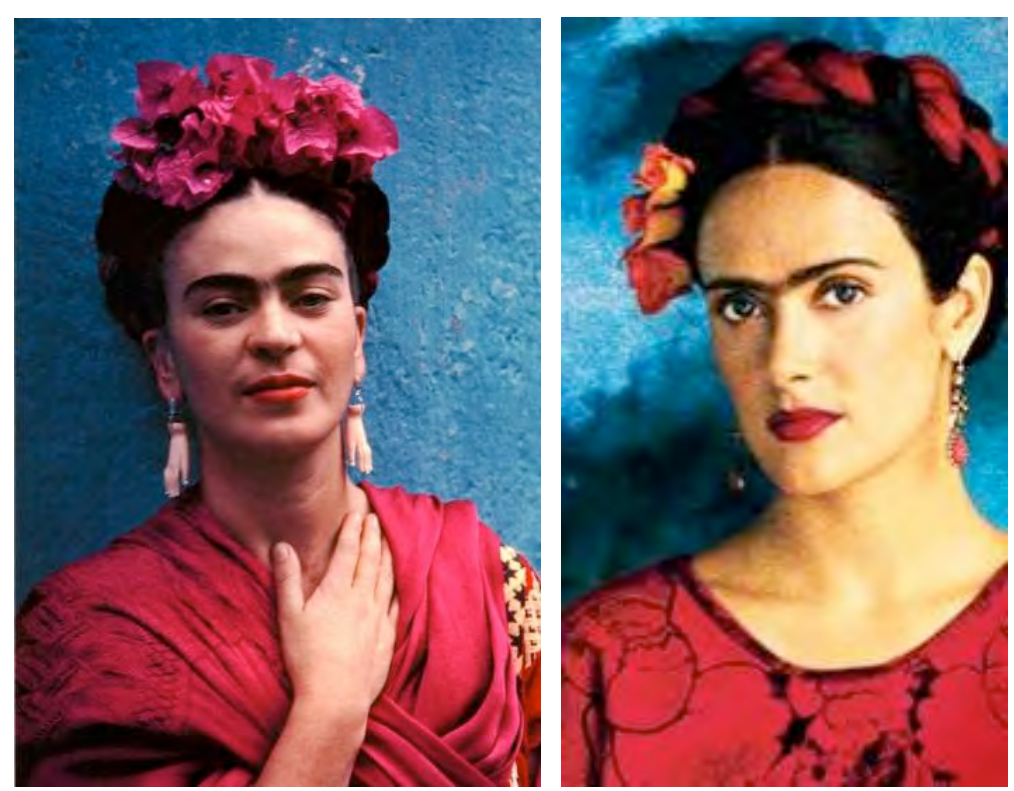

Figura.02 - Lado direito: Retrato da artista Frida Kahlo. Técnica: fotografia.

Lado esquerdo: Fotografia do filme: Frida, 2002. Direção: Julie Taymor

Após as referências citadas retoma-se o trabalho artístico realizado no momento em que se percebeu a semelhança entre a face pintada na história da Arte e a face da pessoa do cotidiano da professora artista. A partir da semelhança ela decide convidar as pessoas para 
participar de um trabalho artístico. Após o aceite a artista explicou a proposta, mostrou em quais traços considerava os rostos parecidos, mostrou o retrato da história da Arte para se falar da obra e do artista (quando a pessoa assina a obra e adquire reconhecimento enquanto artista, o que ocorre, principalmente, no Renascimento), ainda, explicou de que maneira a pintura poderia ocorrer no rosto e o posicionamento do corpo para o retrato e o registro fotográfico. A pintura acontece no momento da aplicação da maquiagem no rosto e continua sendo pintura mesmo a partir da fotografia. Cabe ressaltar que não se trata de um registro despretensioso, pelo contrário, há um cuidado com a fotografia para conferir a recorrência dos rostos.

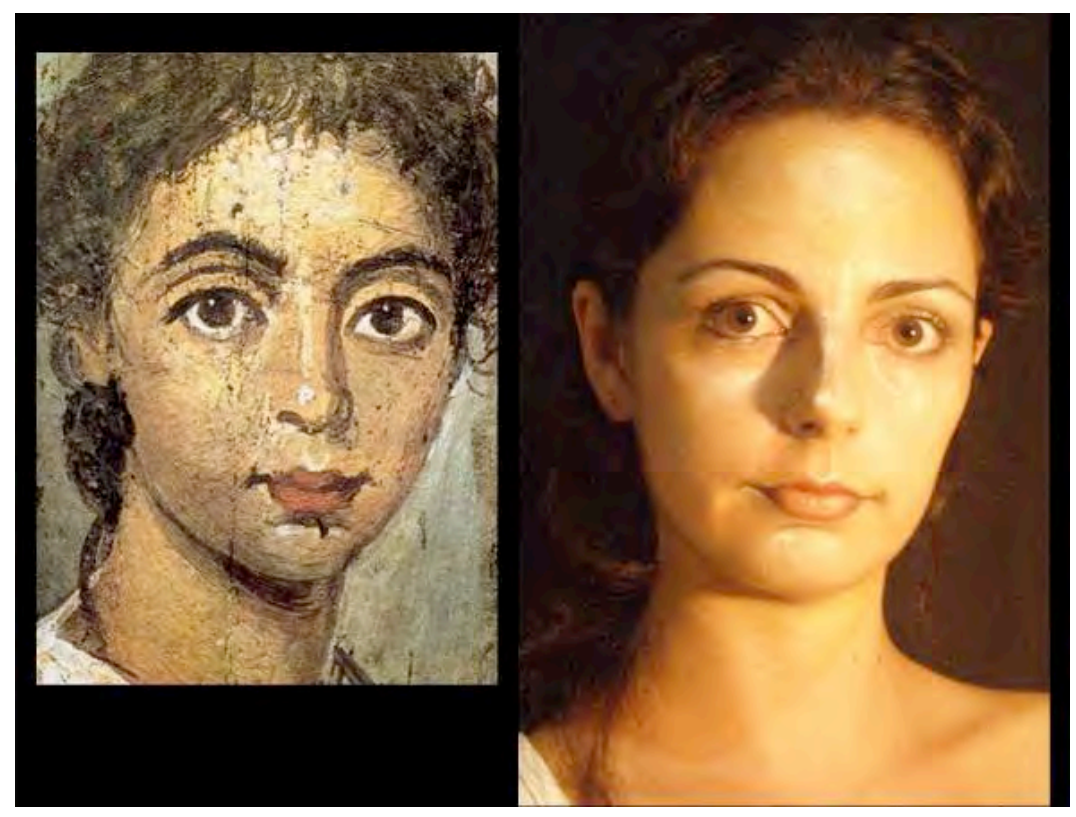

Figura.03 - Lado esquerdo: Retrato funerário de uma jovem. Região de Fayum. Artista desconhecido. Técnica: encáustica sobre madeira, $2^{\circ}$ séc a.C. Lado direito: Incidência. Participação de Paula. Florianópolis, 2010.Técnica: pintura sobre o rosto e fotografia. Dimensão: fotografias em formatos variáveis

Todas as produções ocorreram em Florianópolis com a colaboração de pessoas do entorno da professora artista. A primeira produção ocorreu em uma república de estudantes com a participação de Paula, na aproximação com um retrato funerário de uma jovem da região de Fayum (Figura.03). O segundo trabalho foi realizado na Sala de Pintura do Bloco das Artes Visuais, na Universidade do Estado de santa Catarina (UDESC), com a participação 
de Kamilla, na aproximação com um retrato funerário de uma jovem da região de Fayum (Figura.04).

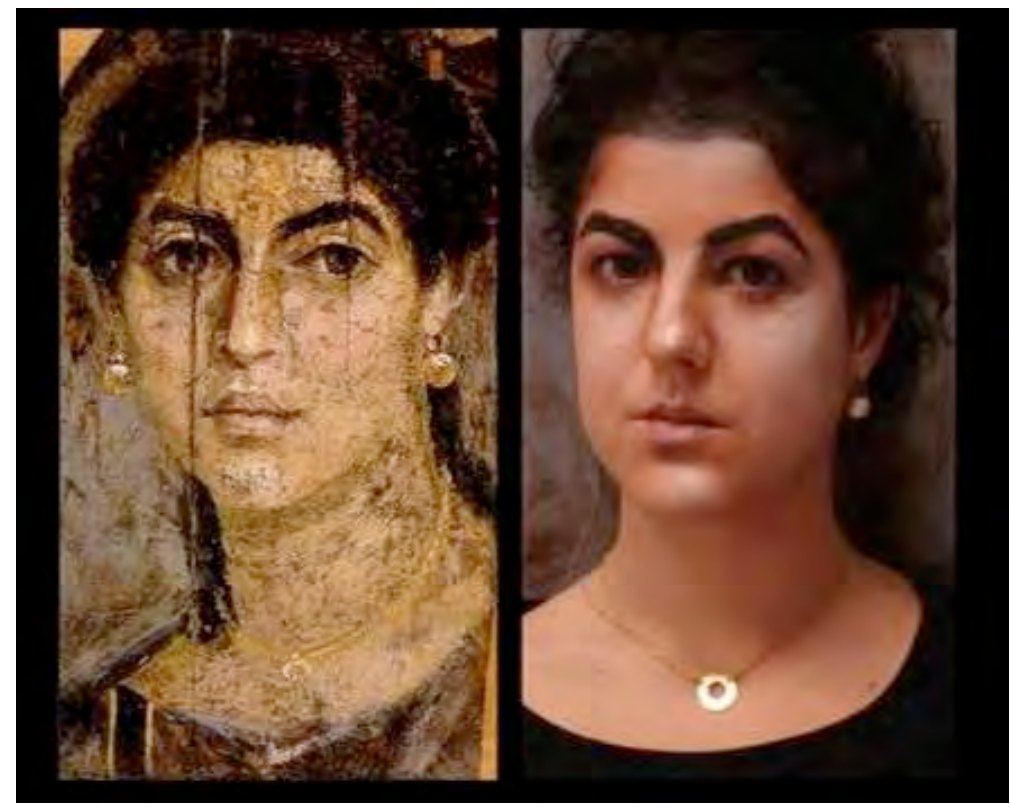

Figura.04 - Lado esquerdo: Retrato funerário de uma jovem. Região de Fayum. Artista desconhecido. Técnica: encáustica sobre madeira, $2^{\circ}$ séc a.C. Lado direito: Incidência. Participação de Kamilla. Florianópolis, 2010.Técnica: pintura sobre o rosto e fotografia. Dimensão: fotografias em formatos variáveis

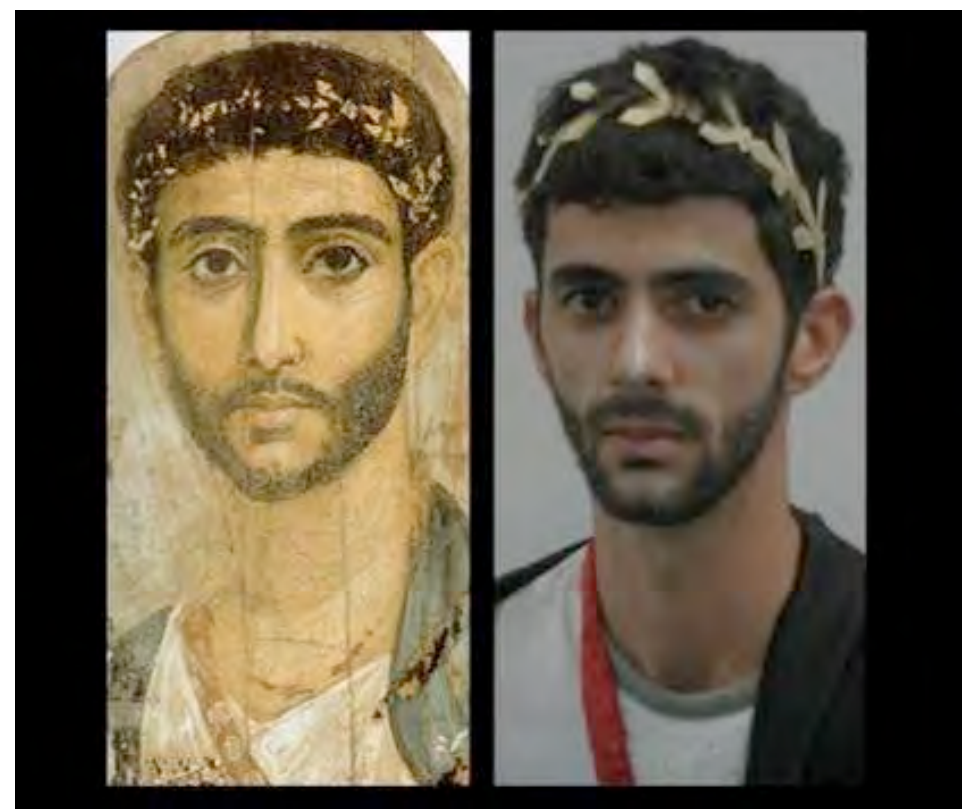

Figura.05 - Lado esquerdo: Retrato funerário de um jovem. Região de Fayum. Artista desconhecido. Técnica: encáustica sobre madeira, $2^{\circ}$ séc a.C. Lado direito: Incidência. Participação de Leandro. Florianópolis, 2010.Técnica: pintura sobre o rosto e fotografia. Dimensão: fotografias em formatos variáveis. 
O terceiro trabalho foi realizado na sala de gravura e no corredor do bloco amarelo do CEART/UDESC, com a participação de Leandro, na aproximação com um retrato funerário de um jovem da região de Fayum (Figura.05). O quarto trabalho foi realizado na Biblioteca da UDESC, com a participação de William, na aproximação com a pintura O Bibliotecário, do artista Arcimboldo (Figura.06). E o quinto trabalho foi produzido na Sala de Pintura da UDESC (Figura.07), com a participação de Renata, na aproximação com a anã pintada na obra As meninas, do artista Diego Velasquez. A Renata foi a única participante que pediu para participar dos trabalhos, pois ela mesma considerava seu rosto parecido com o da anã da pintura de Velasquez, os demais participantes foram convidados.

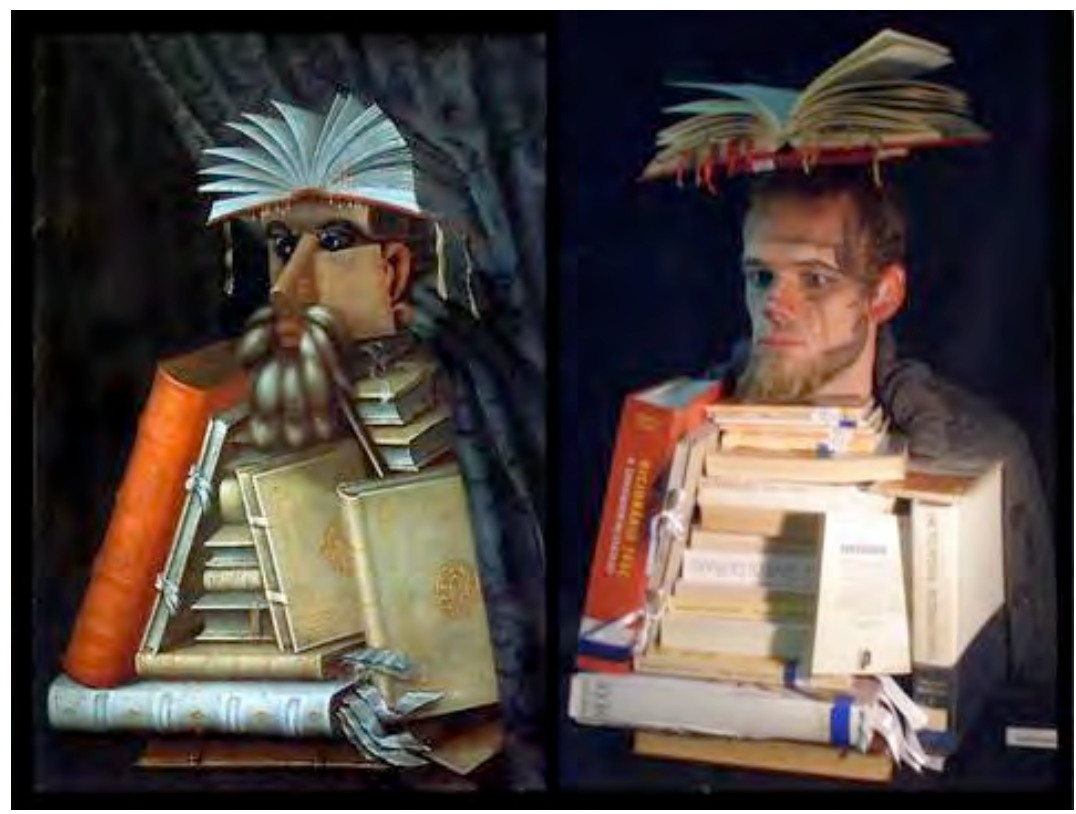

Figura.06 - Lado esquerdo: O Bibliotecário, 1566. Artista: Arcimboldo. Técnica: óleo sobre tela. Dimensões: $97 \mathrm{~cm} \mathrm{x71 \textrm {cm } . ~}$ Lado direito: Incidência. Participação de Willian. Florianópolis, 2010.Técnica: pintura sobre o rosto e fotografia. Dimensão: fotografias em formatos variáveis. 


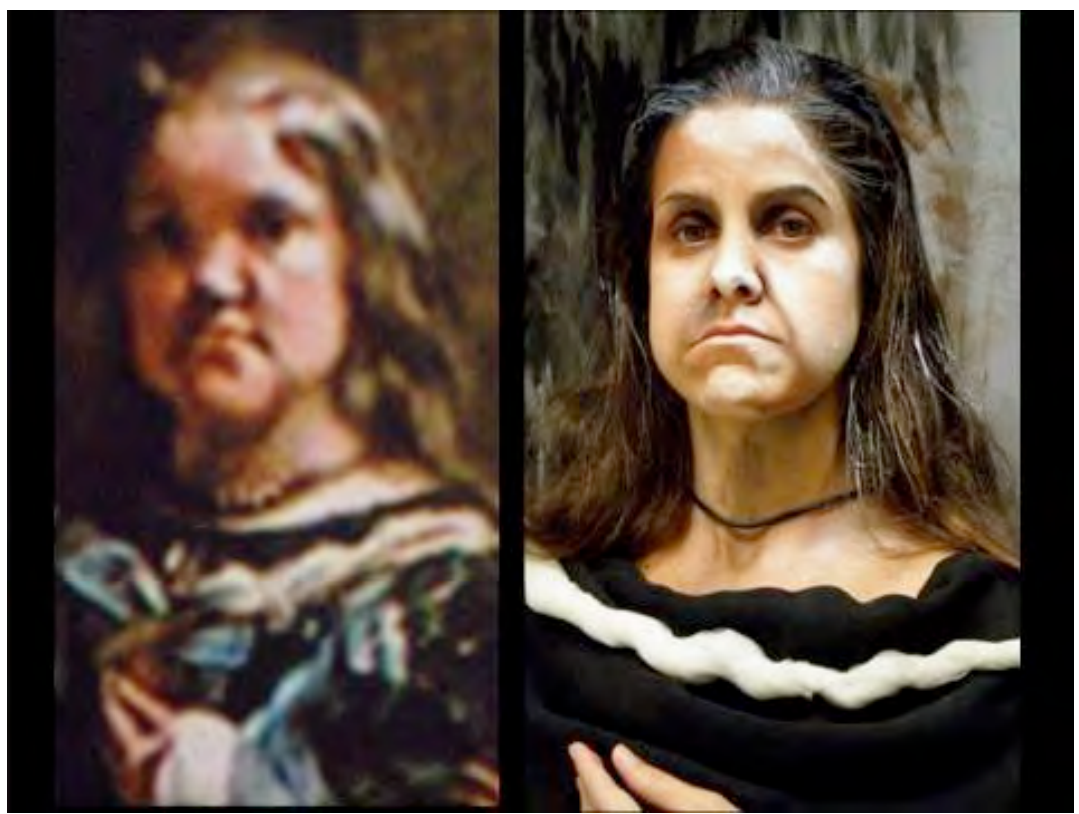

Figura.07 - Lado esquerdo: As meninas, 1656. Artista: Diego Velasquez. Técnica: óleo sobre tela, Dimensões| $318 \mathrm{~cm} \times$ $276 \mathrm{~cm}$. Lado direito: Incidência. Participação de Renata. Florianópolis, 2010.Técnica: pintura sobre o rosto e fotografia. Dimensões: formatos variáveis.

Em alguns momentos da ação o(a) assemelhado(a) se envolve com o trabalho e deseja ser o próprio semelhante. Imaginar situações, fantasiar como se realmente tivesse vivido na época e a vida da pessoa do retrato do qual se partiu. Deseja ser o que não é. Esse desejar ser o que não é se refere a uma característica humana, tão humana quanto o realismo das pinturas que se tornam identificáveis em outros rostos.

Com a pesquisa e o trabalho buscaram-se traços que retornam. "Incidência" questiona o enigma da pintura do passado, com o enigma da vida da pessoa real, na recorrência de seus traços faciais. Nesse confronto de temporalidades, de interesses, de vidas, o assemelhado deseja se tornar o semelhante, deseja ser reconhecida enquanto aquilo que não é. Quando o assemelhado tenta uma aproximação com a vida do semelhante, trata-se de fantasia, de um gozo fabuloso no enigma anacrônico das vidas.

Além da pessoa convidada se projetar mentalmente como sendo outra, durante a pintura e a fotografia percebeu-se outra característica relevante a cerca do material utilizado sobre os rostos. A maquiagem, por exemplo, é utilizada cotidianamente com o intuito de deixar a pessoa mais bela, esconder algum traço indesejado. No entanto, nessa pesquisa, a maquiagem transforma a pessoa, onde ele não mais reconhece seu rosto, se tornando outra, 
normalmente um outro estranho, bizarro, onde os traços indesejados foram acentuados para que se pareça mais com o retrato. Então, ao mesmo tempo em que a pessoa se projeta imaginariamente desejando ser outra, a partir do momento que se olha no espelho com maquiagem não reconhece a si e sim um ser outro, estranho e feio, pois possui traços de tinta que destoam do natural. Ocorre essa ambiguidade de se projetar satisfeito como sendo outra pessoa, mas ao se olhar no espelho, se trata de outro que é estranho e indigesto.

O trabalho apresentado nas Figuras 03, 04, 05, 06 e 07 foi selecionado para participar do $12^{\circ}$ Salão de Artes de Itajaí, sob a curadoria de Josué Mattos, que trouxe como tema as poéticas pessoais em construção. Salão que mostrou obras de diferentes artistas de Santa Cataria e do Brasil. O trabalho foi exposto a partir da impressão fotográfica do registro da ação. As fotografias, cujas dimensões eram de $30 \mathrm{~cm}$ X $20 \mathrm{~cm}$, foram colocadas em uma parede com fundo branco.

\section{Prática Pedagógica}

A prática pedagógica ocorreu posteriormente à prática artística e está diretamente ligada a ela apresentando algumas semelhanças e diferenças. Ao realizar uma sequência de aulas para a turma do $8^{\circ}$ ano, acerca dos diferentes gêneros da pintura como a pintura histórica ou cenas mitológicas, natureza-morta, paisagem, até o retrato. Quando se apresentou uma série artistas que produziram retratos e autorretratos ao longo da história da Arte e, ao final, a professora apresentou seu próprio trabalho intitulado Incidência. A partir deste trabalho os estudantes demonstraram interesse em realizar, na escola, algo que se aproximasse ao que a professora havia feito.

A professora respondeu afirmativamente acerca da possibilidade e questionou quais os retratos que mais os interessaram, se havia alguém na turma com os traços parecidos ou se conheciam alguém para convidar e participar. Os estudantes falaram que gostariam de participar e foram indicando os possíveis retratos para a realização do exercício artístico na escola.

$\mathrm{Na}$ aula seguinte foi possível estudar os retratos selecionados e dividir tarefas para que cada estudante ou grupo ficasse responsável por diferentes tarefa e trazer os materiais para a 
aula, como: iluminação, roupas, adereços, maquiagem, tintas, pano de fundo, tecidos em cores diversas, fitas para realizar ajustes, pregos, martelo, grampeador para madeira, esboço dos cenários e máquinas fotográficas para o registro do exercício artístico. As tarefas foram distribuídas conforme cada estudante afirmava ter o material disponível em casa.

A cada aula foi possível realizar uma produção com o trabalho coletivo da turma. Para a montagem do cenário, a realização da maquiagem e posição dos estudantes a serem fotografados utilizou-se como referência a pintura original do artista selecionado, que foi impressa em folha A4. As obras que os estudantes selecionaram foram: Os Amantes, do artista René Magritte, produzida no ano de 1928; A Primavera, do artista Sandro Botticelli, produzida em 1482; e Moça com Brinco de Pérola, produzida em 1665, pelo artista Johannes Vermeer.

A primeira experiência realizada ocorreu a partir da obra Os Amantes, do artista René Magritte (Figura.08). A turma se organizou e trouxe os materiais, realizara a montagem do cenário, a escolha das roupas, dos panos e observaram a posição que consideraram adequada para realizar o registro fotográfico. A professora fotografou a ação juntamente com os estudantes que levaram máquina fotográfica e demonstraram interesse em registrar ou emprestar seu equipamento para os colegas. Dois estudantes haviam se colocado a disposição para serem os personagens da pintura e solicitaram a autorização dos pais para participar do exercício artístico.
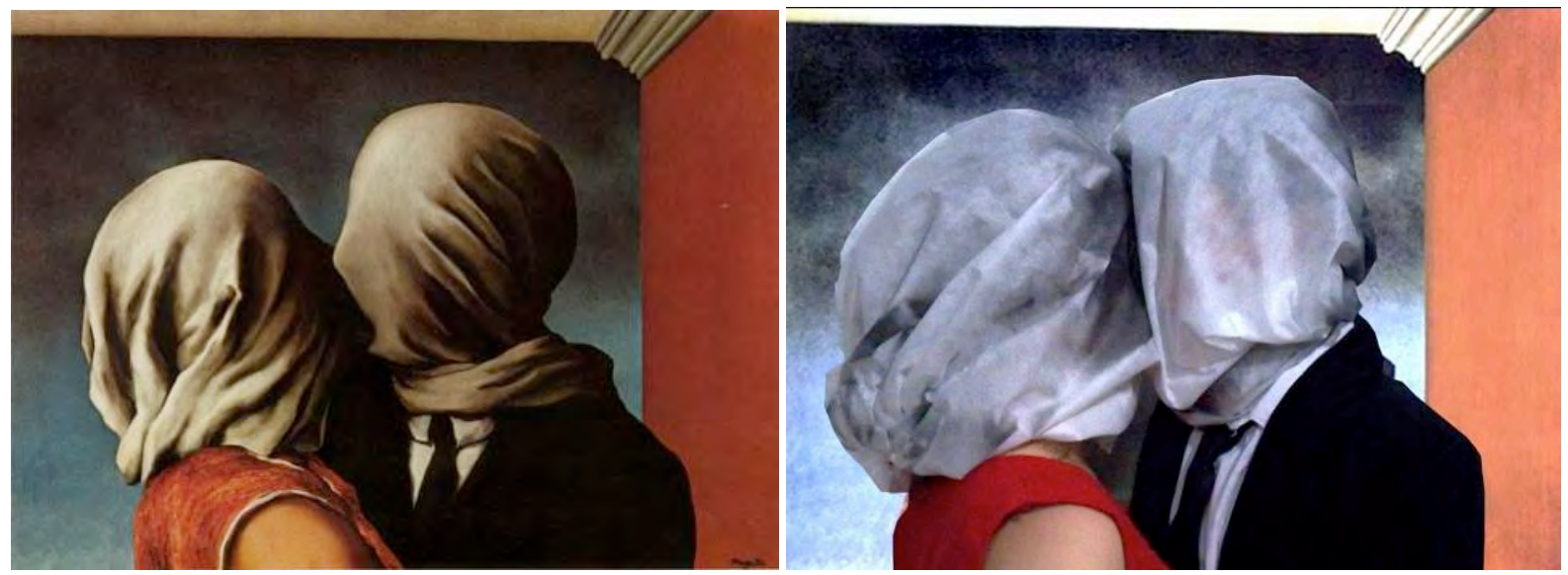

Figura.08 - Lado esquerdo: Os Amantes, 1928. Artista: René Magritte. Técnica: óleo sobre tela, Dimensões: $\lceil 54 \mathrm{~cm}$ x $73 \mathrm{~cm}$. Lado direito: Incidência. Participação de Betina, Luis Fernando da turma do $8^{\circ}$ Ano do Ensino Fundamental. São Paulo das 

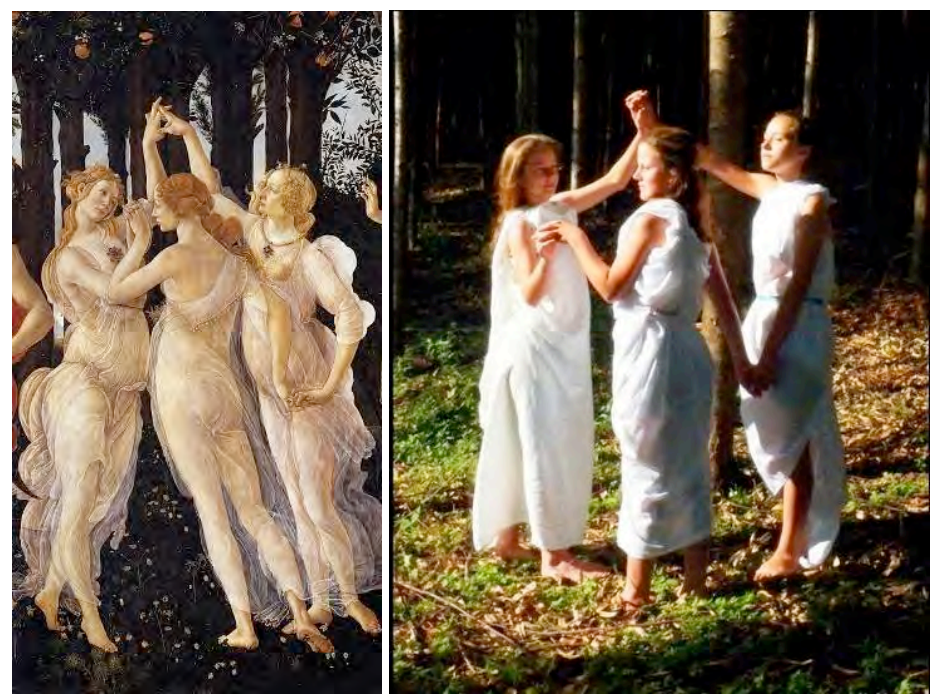

Figura.09 - Lado esquerdo: Recorte da obra A Primavera, 1482. Artista: Sandro Botticelli. Técnica: têmpera. Lado direito: Incidência. Participação de Claudiane, Aline, Juliane e a turma do $8^{\circ}$ Ano do Ensino Fundamental. São Paulo das MissõesRS, 2013.Técnica: fotografia e montagem. Dimensões: formatos variáveis. Exposição: Breve passeio pela História da Arte, 2013

A segunda experiência realizada ocorreu a partir de um recorte da pintura A Primavera, do artista Sandro Botticelli. A obra completa apresenta uma cena mitológica com diferentes situações e histórias ocorrendo em uma mesma pintura. Optou-se por realizar um recorte da obra, onde consta as três graças, para se distanciar um pouco da cena mitológica e se aproximar do retrato de corpo inteiro das moças. A representação das três graças se repete ao longo da história da Arte com diferentes artistas como: Rafael Sanzio, Peter Paul Rubens, Carle Van Loo e Lucas Cranach na pintura, assim como Antonio Canova na escultura.

A turma se organizou para trazes os panos brancos, os cintos, os acessórios e a maquiagem. A fotografia ocorreu no terreno ao lado da escola e obtivemos o consentimento da direção para a turma realizar esta aula neste espaço. As estudantes se arrumaram e os demais observaram a posição que julgaram adequada para realizar o registro fotográfico. A professora fotografou a ação juntamente com os estudantes que levaram máquina fotográfica e demonstraram interesse em registrar ou emprestar seu equipamento para os colegas. A seleção da fotografia, enquanto registro da ação, foi realizada em conjunto com a turma na aula seguinte ao exercício artístico (Figura.09). 
A terceira experiência realizada ocorreu a partir da obra Moça com Brinco de Pérola, do artista Johannes Vermeer (Figura.10). A turma assistiu o filme de mesmo título e, a partir dele, houveram os comentários de que a estudante Karen se parecia com a pintura. A estudante se colocou a disposição e seus colegas trouxeram o material que consistia em cores diferentes de panos para a roupa e o fundo, assim como a maquiagem e o brinco de pérola.
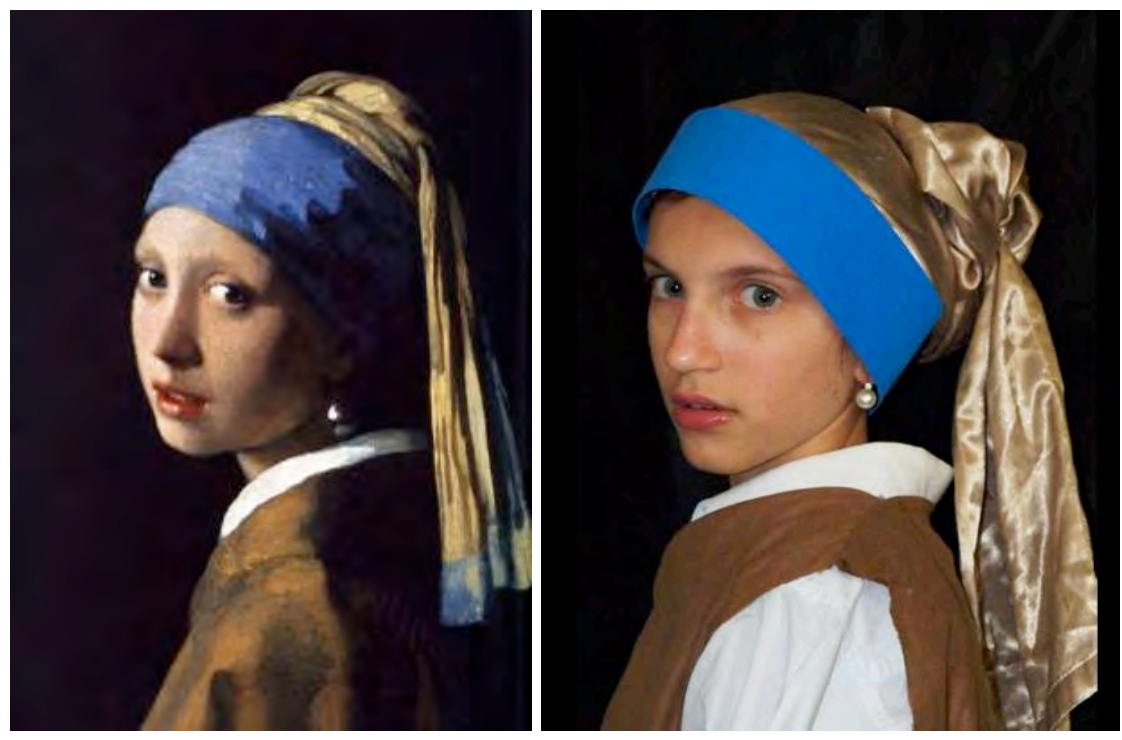

Figura.10 - Lado direito: Moça com Brinco de Pérola, 1665. Artista: Johannes Vermeer. Técnica: óleo sobre tela. Dimensões: 46,5cm X 40cm. Lado direito: Incidência. Participação de Karen e a turma do $7^{\circ}$ Ano do Ensino Fundamental da Escola Rieger. São Paulo das Missões-RS, 2013.Técnica: fotografia. Dimensões: formatos variáveis. Exposição: Breve passeio pela História da Arte, 2013

A turma colaborou na montagem do cenário, com a maquiagem e com a amarração do turbante. Enquanto a aluna se vestia e recebia ajuda de outras estudantes, o restante da turma arrumava o cenário. Os estudantes observaram a posição adequada para realizar o registro fotográfico, a professora fotografou a ação juntamente com os estudantes que levaram máquina fotográfica e demonstraram interesse em registrar ou emprestar seu equipamento para os colegas.

Os três exercícios artísticos realizados fizeram parte da exposição Breve Passeio pela História da Arte (2013), organizado pela professora artista, que contou com a participação das turmas do $6^{\circ}$ ao $9^{\circ}$ ano das escolas municipais as quais a professora lecionava. As produções dos estudantes expostas estavam direcionadas para a cronologia da história da Arte e grande 
parte dos movimentos artísticos nela existente. A exposição ocorreu dentro das atrações da Semana da Cultura do Município de São Paulo das Missões. Além da exposição foi publicada uma matéria no Jornal Gazeta do Povo (MÜLLER, 2013). Cabe salientar que sem a participação das turmas e o empenho dos estudantes na produção e montagem da exposição, ao longo de dias e noites, nada teria sido possível.

\section{Considerações}

A proposta pedagógica de representar algumas pessoas como em retratos estudados na história da Arte adveio dos próprios estudantes, após estudar os gêneros da pintura e visualizar a produção artística da professora, com ênfase no retrato, em uma série de trabalhos intitulado Incidência. A partir da manifestação estudantil foi montada uma proposta a ser realizada em uma sequência de aulas onde os retratos selecionados foram estudados, juntamente com a biografia e outros trabalhos do artista, para depois decompor os elementos constituintes da obra e dividir tarefas, para que os estudantes trouxessem o material necessário para realizar a pintura no rosto, o uso dos adereços, a montagem do cenário e o registro fotográfico da ação, tendo por base o retrato selecionado e impresso em folha A4 para ser visualizado constantemente.

O presente trabalho embasou-se no retrato e sua representação enquanto gênero artístico da pintura e que se torna referência em diferentes procedimentos artísticos como no caso da fotografia. Optou-se por não entrar em uma discussão aprofundada da fotografia em virtude da amplitude que o trabalho atingiria e porque a prática artística, denominada Incidência, advém da pintura (ao se pintar rostos de pessoas para depois fotografar e realizar um paralelo com as pinturas de retrato da história da Arte). Nesse sentido, a fotografia está como registro e modo de apresentação do trabalho e não como técnica ou referência artística principal.

Ao observar a prática artística e pedagógica talvez o pensamento se direcione para a reflexão de que pode se tratar de uma série de releituras de obras. No entanto, o objetivo não é trabalhar e discutir o conceito de releitura e sim, ser o mais fiel possível as pinturas selecionadas para poder questionar a própria pintura, os retratos, a recorrência de rostos, a 
semelhança do ser humano, os traços recorrentes entre pessoas desconhecidas que viveram em tempos e locais totalmente diferentes.

Rostos retratados há milênios, por vezes lembrados e esquecidos e agora se apresentam corporeamente aos olhos dos participantes. Não como os mesmos que foram, mas a partir da recorrência dos rostos, a cumplicidade de traços que retornam em outras faces reconhecíveis. As obras que fazem parte da série Incidência respaldam a ideia de que o naturalismo de algumas pinturas parece tão real que se torna possível reconhecer a pessoa do passado em outra pessoa do presente a partir de sua fisionomia feita com tinta.

O trabalho artístico se converte em ação pedagógica a partir do interesse dos estudantes em realizar exercícios artísticos próximos ao trabalho da professora artista. Os estudantes se dedicaram e estudaram as obras, colaboraram assiduamente no processo, na produção, no registro e na montagem de um trabalho maior que foi a exposição Breve Passeio pela História da Arte, exposição na qual constaram os trabalhos realizados (Figura 08, 09 e 10). O retorno satisfeito dos estudantes e da comunidade escolar é o que alimenta a perspectiva do trabalho humano e enriquecedor que a docência em meio a Arte é capaz de proporcionar.

\section{REFERENCIAS}

DEBRAY, Régis. Vida e morte da imagem: uma história do olhar no ocidente. Petrópolis: Vozes, 1994

DIDI-HUBERMAN, Georges. O rosto e a terra: onde começa o retrato, onde se ausenta o rosto. Tradução de Sonia Taborda. Porto Alegre: Porto Alegre, v.9, n. 16, 1998, p. 61-82

O que vemos, o que nos olha. São Paulo: Editora 34, 1998, p. 29-36

MÜLLER, Maristela. Breve Passeio pela História da Arte. Cerro Largo: Jornal A Gazeta do Povo, 2013

SONTAG, Susan. Sobre Fotografia. Ensaios. São Paulo: Companhia das Letras, 2004 
RETRATO . In: ENCICLOPÉDIA Itaú Cultural de Arte e Cultura Brasileiras. São Paulo: Itaú Cultural, 2017. Acesso em: 19 de Abr. 2017. Disponível em:

$<$ http://enciclopedia.itaucultural.org.br/termo364/retrato>

$12^{\circ}$ Salão de Artes de Itajaí. Poéticas Pessoais em construção. Curadoria de Josué Mattos. Itajaí/SC. De 21 de junho a 22 de julho de 2010

Recebido em 25 de abril de 2016 Aprovado em 31 de maio de 2017 